\title{
Sex Differences in $\mu$-Opioid Receptor Expression in the Rat Midbrain Periaqueductal Gray Are Essential for Eliciting Sex Differences in Morphine Analgesia
}

\author{
Dayna R. Loyd, Xioaya Wang, and Anne Z. Murphy \\ Neuroscience Institute, Center for Behavioral Neuroscience, Georgia State University, Atlanta, Georgia 30302-4010
}

\begin{abstract}
Opioid-based narcotics are the most widely prescribed therapeutic agent for the alleviation of persistent pain; however, it is becoming increasingly clear that morphine is significantly less potent in women compared with men. Morphine primarily binds to $\mu$-opioid receptors (MORs), and the periaqueductal gray (PAG) contains a dense population of MOR-expressing neurons. Via its descending projections to the rostral ventromedial medulla and the dorsal horn of the spinal cord, the PAG is considered an essential neural substrate for opioid-based analgesia. We hypothesized that MOR expression in the PAG was sexually dimorphic, and that these sex differences contribute to the observed sex differences in morphine potency. Using immunohistochemistry, we report that males had a significantly higher expression of MOR in the ventrolateral PAG compared with cycling females, whereas the lowest level of expression was observed in proestrus females. CFA-induced inflammatory pain produced thermal hyperalgesia in both males and females that was significantly reversed in males with a microinjection of morphine into the ventrolateral PAG; this effect was significantly greater than that observed in proestrus and estrus females. Selective lesions of MOR-expressing neurons in the ventrolateral PAG resulted in a significant reduction in the effects of systemic morphine in males only, and this reduction was positively correlated with the level of MOR expression in the ventrolateral PAG. Together, these results provide a mechanism for sex differences in morphine potency.
\end{abstract}

Key words: dermorphin-saporin; intra-vlPAG; estrous cycle; pain; inflammation; opiate

\section{Introduction}

It is becoming increasingly clear that morphine is more potent in male compared with female rats, with similar, although not unequivocal, effects observed in humans (Cepeda et al., 2002; Cepeda and Carr, 2003; Miller and Ernst, 2004). Sex differences in morphine analgesia have been demonstrated in multiple preclinical studies using both acute and persistent orofacial (Okamoto et al., 2005), visceral (Ji et al., 2006; 2007) and somatic (Bartok and Craft, 1997; Cicero et al., 1997; Boyer et al., 1998; Kest et al., 1999; Barrett et al., 2001; Cook and Nickerson, 2005; Wang et al., 2006) pain models, with $\mathrm{ED}_{50}$ values two times higher in female compared with male rats (Wang et al., 2006; Ji et al., 2007). Importantly, sex differences in opiate sensitivity are not due to the pharmacokinetics of morphine because no sex difference has been reported in serum or brain levels of morphine, and elimination and metabolic rates are comparable between sexes (Cicero et al., 1996; Craft et al., 1996; Cicero et al., 1997; Sarton et al., 2000). Rather, sex differences in morphine analgesia are likely

\footnotetext{
Received Aug. 28, 2008; revised Aug. 28, 2008; accepted Nov. 10, 2008.

This work was supported by National Institutes of Health Grants DA16272 and P50 AR49555 awarded to A.Z.M. We thank Dr. Robert Elde of the University of Minnesota for his generous gift of the MOR1 antibody used in experiment 1. We acknowledge the technical assistance of Geary R. Smith with receptor immunohistochemistry and Malcolm E. Johns with receptor autoradiography. We sincerely thank Dr. MichaelS. Gold, for comments on a previous draft of this manuscript.

Correspondence should be addressed to Dr. Anne Z. Murphy, Neuroscience Institute, Georgia State University, PO Box 5030, Atlanta, GA 30302-5030. E-mail: amurphy@gsu.edu.

DOI:10.1523/JNEUROSCI.4123-08.2008

Copyright $\odot 2008$ Society for Neuroscience $\quad 0270-6474 / 08 / 2814007-11 \$ 15.00 / 0$
}

due to differences in opiate receptor density, binding and localization, as well as sex differences in the anatomy and physiology of opiate-responsive neural circuits (Loyd and Murphy, 2006, 2008; Loyd et al., 2007, 2008).

The midbrain periaqueductal gray (PAG) and its descending projections to the rostral ventromedial medulla (RVM) constitute an essential neural circuit for opioid-based analgesia (Basbaum et al., 1976, 1978; Fields and Basbaum, 1978; Basbaum and Fields, 1979; Behbehani and Fields, 1979; Shah and Dostrovsky, 1980; Abols and Basbaum, 1981; Beitz, 1985; Beitz and Shepard, 1985). Administration of $\mu$-opioid receptor (MOR) agonists into the PAG produces potent analgesia that is blocked by central or systemic administration of the opioid antagonist naloxone ( $\mathrm{Sa}$ toh et al., 1983; Jensen and Yaksh, 1986; Bodnar et al., 1988). Similarly, direct administration of MOR antagonists into the PAG blocks the antinociceptive effects of systemic morphine (Wilcox et al., 1979; Ma and Han, 1991; Zhang et al., 1998) indicating that the PAG is an essential locus for exogenous opioidmediated analgesia.

The ventrolateral PAG (vlPAG) contains a high density of MOR (Mansour et al., 1986, 1987; Kalyuzhny et al., 1996; Gutstein et al., 1998; Commons et al., 1999, 2000; Wang and Wessendorf, 2002) and $\sim 27-50 \%$ of PAG neurons projecting to the RVM express MOR (Commons et al., 2000; Wang and Wessendorf, 2002). Unfortunately, studies examining the distribution of MOR within the PAG-RVM circuit were conducted exclusively in males. The vlPAG is a critical site mediating the analgesic effects 


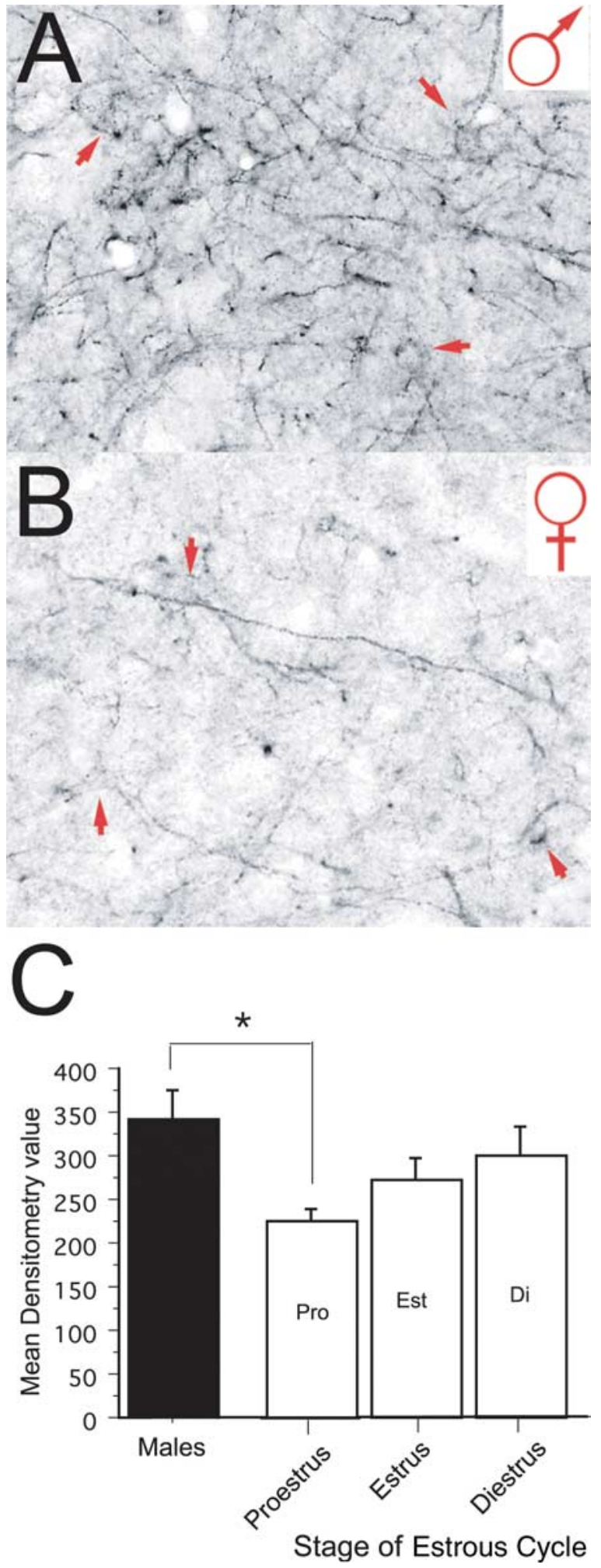

Figure 1. $\quad \boldsymbol{A}, \boldsymbol{B}$, Photomicrograph depicting $\mu$-opioid receptor immunoreactivity in the caudal ventrolateral PAG (bregma -8.00 ) in a male $(\boldsymbol{A})$ and a female $(\boldsymbol{B})$ rat. Arrows denote MORimmunoreactive cell bodies. $C$, Mean densitometry value of $\mu$-opioid receptor immunoreactivity in male (closed bar) and proestrus, estrus, and diestrus females (open bars) averaged across the caudal PAG (bregma -7.04 to -8.30 ). *Significant effect.

of morphine, yet despite profound sex differences in morphine analgesia, surprisingly little is known about the distribution and function of MOR in females. The present studies tested the hypothesis that sex differences in MOR expression within the

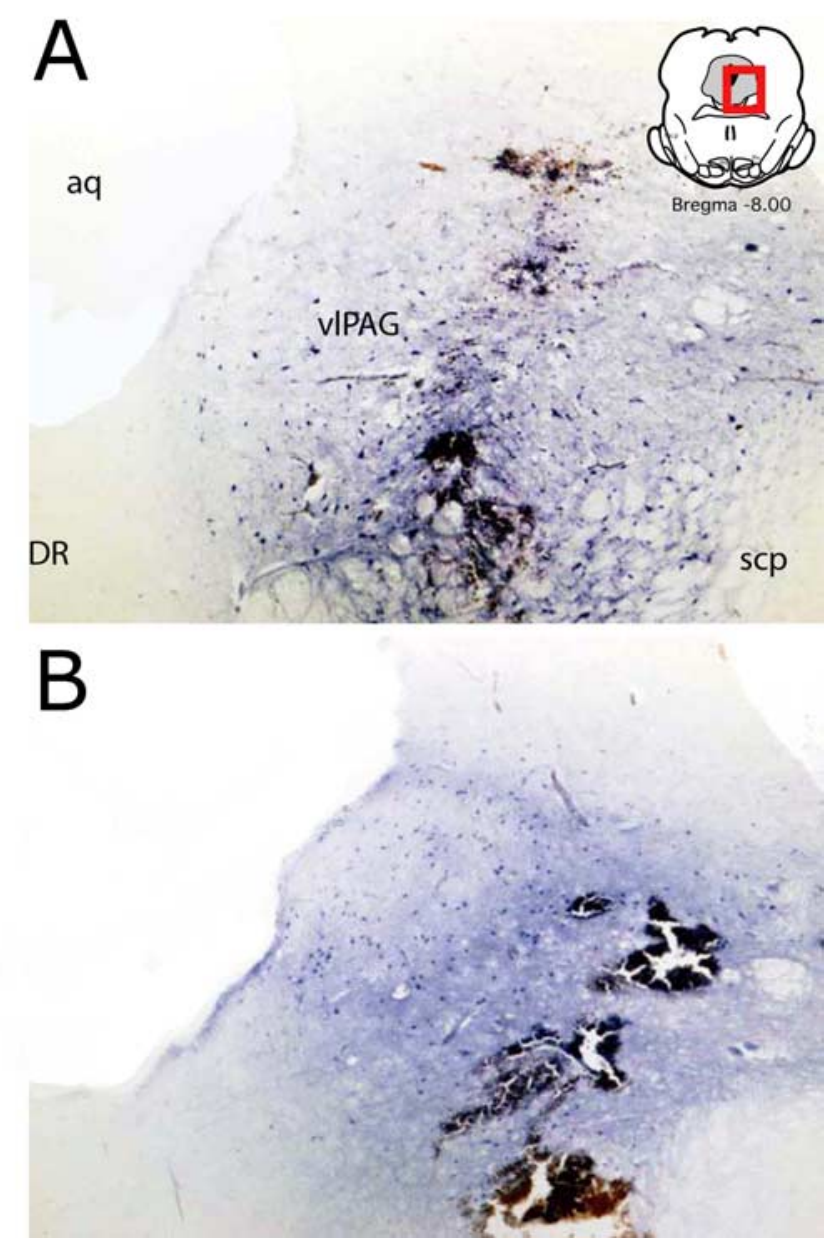

Figure 2. Photomicrograph of an intra-PAG injection site in the caudal ventrolateral PAG (bregma -8.00 ) of a representative male $(\boldsymbol{A})$ and female $(\boldsymbol{B})$ rat. aq, Aqueduct; $v \mathrm{VPAG}$, ventrolateral periaqueductal gray; DR, dorsal raphe; scp, superior cerebellar pedunculus.

vlPAG provide a mechanism underlying the sexually dimorphic effects of morphine. This hypothesis was tested in a series of anatomical and behavioral studies to establish the relationship between sex, antinociceptive potency of intra-PAG morphine and the density of MOR in the vlPAG.

\section{Materials and Methods \\ Subjects}

Adult weight-matched $(250-350 \mathrm{~g})$ intact male and cycling female Sprague Dawley rats were used in these experiments (Zivic-Miller). Rats were housed in same-sex pairs on a 12:12 h light:dark cycle. Access to food and water was ad libitum throughout the experiment except during surgery. These studies were performed in compliance with the Institutional Animal Care and Use Committee at Georgia State University and the guidelines of the Committee for Research and Ethical Issues of the International Association for the Study of Pain (IASP) and the National Institutes of Health. All efforts were made to reduce the number of animals used in these experiments and to minimize any possible suffering by the animal.

\section{Vaginal cytology}

Vaginal lavages were performed daily beginning 2 weeks before testing to confirm that all female rats were cycling normally and to keep daily records on the stages of their cycle in respect to experimental testing. Proestrus was identified as a predominance of nucleated epithelial cells and estrus was identified as a predominance of cornified epithelial cells. Diestrus 1 was differentiated from diestrus 2 by the presence of leuko- 


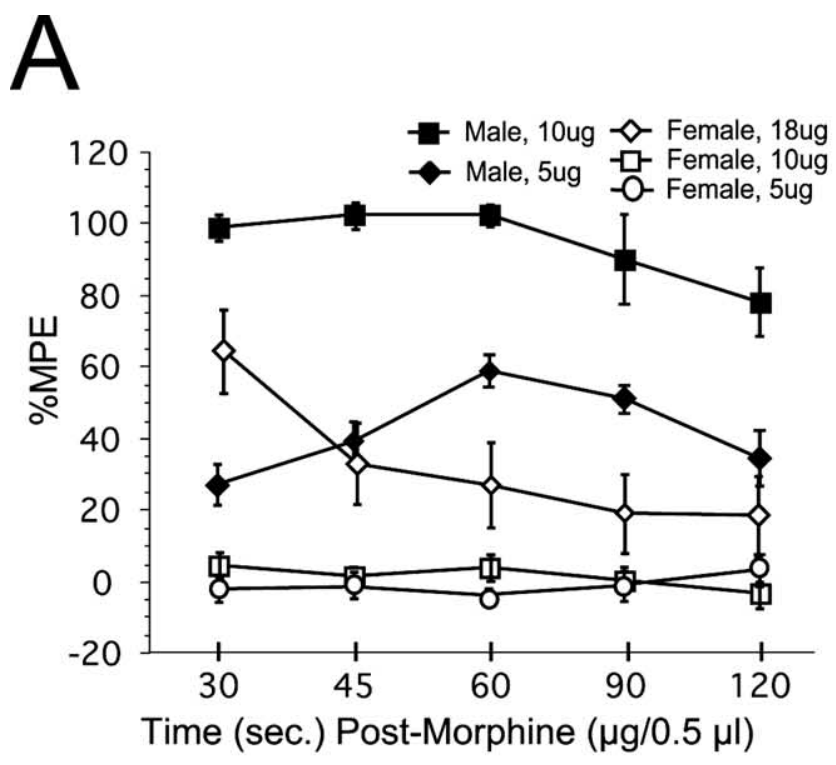

B

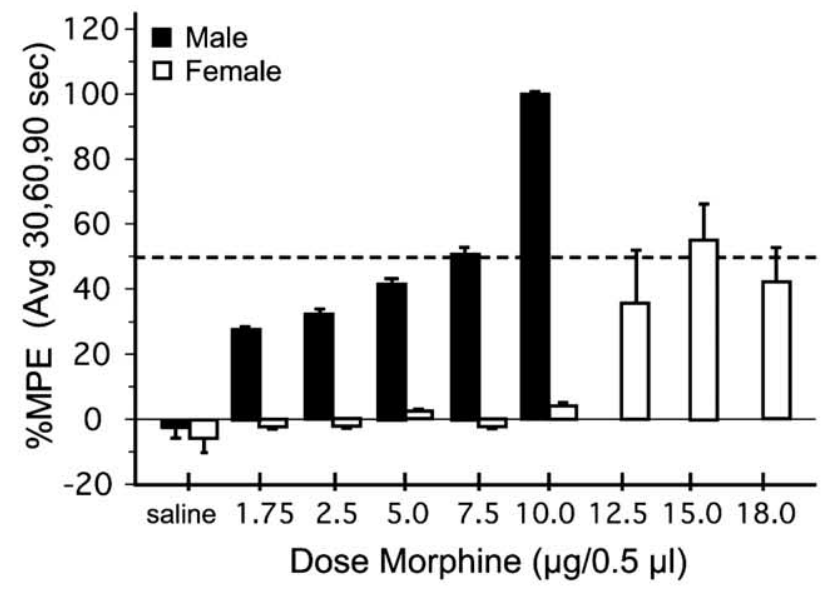

C

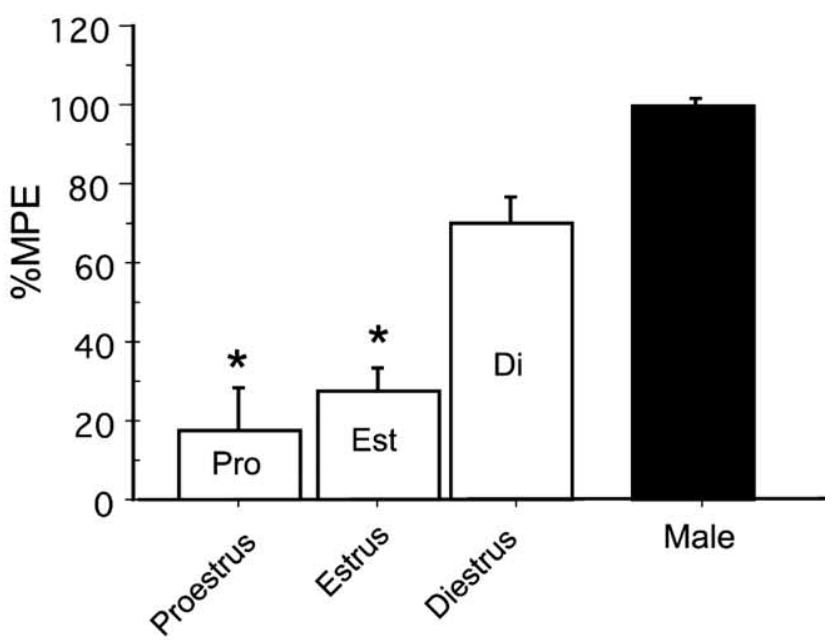

Stage of Estrous Cycle cytes. However, because there were no significant differences noted in either the anatomy or behavior of diestrus 1 and diestrus 2 animals, these data are pooled (diestrus). Rats that appeared between phases were noted as being in the more advanced stage.

\section{Intra-vlPAG cannula implantation}

Intact males $(n=30)$ and cycling females $(n=34)$ were deeply anesthetized with a mixture of ketamine/xylazine/acepromazine (50, 3.3, 3.3 $\mathrm{mg} / \mathrm{kg}$, i.p.; Henry Shein). Guide cannulas (22 gauge; $5.0 \mathrm{~mm}$; Plastics One) were lowered bilaterally into the ventrolateral PAG using the following coordinates (in mm): AP: +0.75 lambda; ML: 0.60; DV: -3.5 . Cannula skull screws and dental acrylic were applied to secure placement. Cannulas were flushed every $48-72 \mathrm{~h}$ with $0.5 \mu \mathrm{l}$ of saline over a $60 \mathrm{~s}$ period to acclimate the animals to the injection procedure and maintain cannula patency.

\section{Lesions of $\mu$-opioid receptor-expressing PAG neurons}

Intact males $(n=11)$ and cycling females $(n=11)$ were deeply anesthetized with a mixture of ketamine/xylazine/acepromazine (50, 3.3, 3.3 $\mathrm{mg} / \mathrm{kg}$, i.p.; Henry Shein). Dermorphin-saporin (DermSAP; MOR agonist-saporin cytotoxin conjugate; Advanced Targeting Systems) or blank-saporin (BlankSAP; nonsense peptide-saporin cytotoxin control conjugate; Advanced Targeting Systems) were freshly diluted from stock (DermSap $0.91 \mu \mathrm{g} / \mu \mathrm{l}, 46.9 \mu \mathrm{M}$; BlankSAP $1.5 \mu \mathrm{g} / \mu \mathrm{l}, 46.9 \mu \mathrm{M} ; 32 \mathrm{kDa}$ ) and stored on ice during experimental procedures. DermSAP $(n=6$ males; $n=6$ females) or BlankSAP ( $n=5$ males; $n=5$ females $)$ was injected into the ventrolateral PAG (coordinates in mm): AP: +0.75 lambda; ML: 0.60; DV: - 3.5) using a $1 \mu$ l Hamilton syringe. DermSAP (3 pmol/400 nl; $7.5 \mu \mathrm{M}$ ) or BlankSAP (3 pmol/400 nl; $7.5 \mu \mathrm{M}$ ) was microinjected over $30 \mathrm{~s}$. This procedure was repeated on the contralateral side. Saporin has been previously shown to have no effect in the absence of conjugation (Porreca et al., 2001; Burgess et al., 2002; Vera-Portocarrero et al., 2006). In addition, dermorphin has been shown to have a high binding affinity selective for the $\mathrm{MOR}\left(\mathrm{K}_{\mathrm{i}}\right.$ value of $\left.0.7 \mathrm{~mm}\right)$ and that conjugation to saporin does not significantly alter its binding affinity $\left(\mathrm{K}_{\mathrm{i}}\right.$ value of $0.1 \mathrm{~nm}$; Porreca et al., 2001). This technique has been previously been shown to result in a significant attenuation of MOR expression in the RVM (Porreca et al., 2001) and the spinal cord (Kline and Wiley, 2008). Loss of MOR containing neurons was confirmed in the present study using both immunohistochemistry and autoradiography. Lack of complete cell loss due to the injection procedure was confirmed with immunocytochemistry for neuronal nuclei.

\section{Inflammatory hyperalgesia}

Persistent inflammation was induced by injection of complete Freund's adjuvant (CFA; Mycobacterium tuberculosis; Sigma; $200 \mu \mathrm{l}$ ), suspended in an oil/saline (1:1) emulsion, into the plantar surface of the right hindpaw. Paw diameters were determined using calibrated calipers applied midpoint across the dorsal to plantar surface of both hindpaws before and after induction of inflammation.

\section{Behavioral testing}

Paw withdrawal latencies to a noxious thermal stimulus were determined using the Paw Thermal Stimulator (Univ. California San Diego) as previously described (Hargreaves et al., 1988; Wang et al., 2006). Briefly, for this test, the rat was placed in a clear Plexiglas box resting on an elevated glass plate maintained at $30^{\circ} \mathrm{C}$. After a $1 \mathrm{~h}$ acclimation, a radiant beam of light was positioned under the hindpaw and the time for the rat to remove the paw from the thermal stimulus was electronically recorded as the paw withdrawal latency (PWL). The intensity of the beam was set to

\section{$\leftarrow$}

Figure 3. A, Percent maximal possible effect of intra-PAG morphine administration of 5 and $10 \mu \mathrm{g}$ in male (closed symbols) and 5, 10, and $18 \mu \mathrm{g}$ in female (open symbols) rats. B, Percent maximal possible effect of intra-PAG morphine administration averaged across the time points 30,60 , and 90 min in male (closed bars) and female (open bars) rats. C, Percent maximal possible effect averaged over the 12,15 , and $18 \mu \mathrm{g} / 0.5 \mu$ l doses of intra-PAG morphine in proestrus, estrus, and diestrus females (open bars) compared with intact male (closed bars) rats. *Significant difference compared with males and diestrus females. 

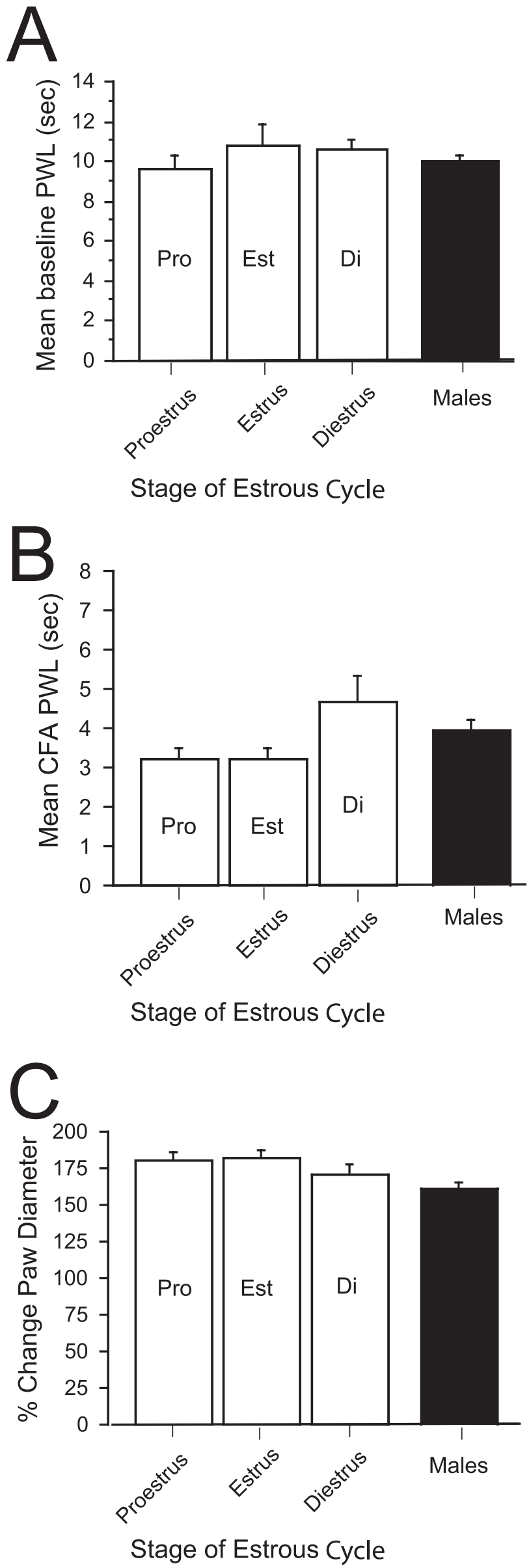

produce basal PWLs of $\sim 10 \mathrm{~s}$. A maximal PWL of $20 \mathrm{~s}$ was used to prevent excessive tissue damage due to repeated application of a noxious thermal stimulus.

\section{Perfusion fixation}

After experimental manipulations, animals were given a lethal dose of Nembutal ( $160 \mathrm{mg} / \mathrm{kg}$, i.p.) and transcardially perfused with $200-250 \mathrm{ml}$ of $0.9 \%$ sodium chloride containing $2 \%$ sodium nitrite as a vasodilator to remove blood from the brain. Immediately after removal of blood, 300 $\mathrm{ml}$ of $4 \%$ paraformaldehyde in $0.1 \mathrm{M}$ phosphate buffer containing $2.5 \%$ acrolein (Polyscience) was perfused through the brain as a fixative. A final rinse with $200-250 \mathrm{ml}$ of the sodium chloride/sodium nitrate solution was perfused through the brain to remove any residual acrolein. Brains were placed in a $30 \%$ sucrose solution and stored at $4^{\circ} \mathrm{C}$.

\section{Immunohistochemistry}

Perfusion-fixed brains were sectioned into $25 \mu \mathrm{m}$ coronal sections with a Leica 2000R freezing microtome and stored free-floating in cryoprotectant-antifreeze solution (Watson et al., 1986) at $-20^{\circ} \mathrm{C}$. A 1:6 series through the rostrocaudal axis of each brain was processed for MOR1 or neuronal nuclei (NeuN) immunoreactivity using standard immunhistochemical techniques as previously described (Murphy and Hoffman, 2001). Briefly, sections were rinsed extensively in potassium PBS (KPBS) immediately followed by a $20 \mathrm{~min}$ incubation in $1 \%$ sodium borohydride. The tissue was then incubated in primary antibody solution rabbit anti-MOR1 (donated by Robert Elde, Ph.D., University of Minnesota, Minneapolis, MN; 1:70,000) or rabbit anti-MOR1 (Abcam; 1:50,000; lot 317653) or mouse anti-NeuN (Millipore Bioscience Research Reagents; 1:50,000; lot 23112968) in KPBS containing $1.0 \%$ Triton-X for $1 \mathrm{~h}$ at room temperature followed by $48 \mathrm{~h}$ at $4^{\circ} \mathrm{C}$. Both MOR1 antibodies were prepared against the synthetic peptide (NHQLENLEAETAPLP) corresponding to amino acids 384-398 of rat MOR1 (Arvidsson et al., 1995; Starowicz et al., 2007). After rinsing with KPBS, the tissue was incubated for $1 \mathrm{~h}$ in biotinylated goat anti-rabbit IgG or anti-mouse (Jackson ImmunoResearch; 1:600), rinsed with KPBS and incubated for $1 \mathrm{~h}$ in an avidin-biotin peroxidase complex (1:10; ABC Elite Kit, Vector Laboratories). After rinsing in KPBS and sodium acetate ( $0.175 \mathrm{M} ; \mathrm{pH} 6.5), \mathrm{MOR} 1$ or NeuN immunoreactivity was visualized as a black reaction product using nickel sulfate intensified $3,3^{\prime}$ diaminobenzidine solution $(2 \mathrm{mg} / 10 \mathrm{ml})$ containing $0.08 \%$ hydrogen peroxide in sodium acetate buffer. After 15-30 min, tissue was rinsed in sodium acetate buffer followed by KPBS. Sections were then mounted out of saline onto gelatin-subbed slides, air-dried, and dehydrated in a series of graded alcohols. Tissue-mounted slides were then cleared in xylene and glass coverslipped using Permount.

\section{Receptor autoradiography}

Dermorphin-saporin- ( $n=4$ males; $n=4$ females $)$ and blank-saporin( $n=4$ males; $n=4$ females) treated animals were rapidly decapitated. Brains were removed rapidly, flash frozen in 2-methylbutane and stored at $-80^{\circ} \mathrm{C}$. Fresh frozen tissue was cut in a $1: 4$ series of $20 \mu \mathrm{m}$ coronal sections at $-20^{\circ} \mathrm{C}$ with a Leica CM3050S cryostat, immediately mounted onto glass slides and stored at $-80^{\circ} \mathrm{C}$. Slides were dried and fixed in $4 \%$ paraformaldehyde followed by rinses in $50 \mathrm{~mm}$ Tris buffer, $\mathrm{pH}$ 7.4, containing $100 \mathrm{~nm} \mathrm{NaCl}$. Slides were then placed in a tracer buffer containing tritiated DAMGO (1 nM; GE Healthcare) for $60 \mathrm{~min}$ followed by a series of rinses in $50 \mathrm{~mm}$ Tris buffer, $\mathrm{pH} 7.4$, containing $\mathrm{MgCl}_{2}$. Tissue was allowed to try and placed on autoradiographic film for 5 weeks at which point films were developed with a FujiFilm BAS 5000.

\section{Densitometry}

For immunohistochemistry data, 12-bit grayscale images were captured using a QImaging Retiga EXi CCD camera and IPLab Image Analysis$$
\leftarrow
$$

Figure 4. A, Mean paw withdrawal latency in seconds to a thermal stimulus in proestrus, estrus, and diestrus female (open bars) compared with male (closed bars) rats. $\boldsymbol{B}$, Mean paw withdrawal latency in seconds to a thermal stimulus after $24 \mathrm{~h}$ of (FA-induced inflammation in proestrus, estrus, and diestrus female (open bars) compared with male (closed bars) rats. C, Percent change in paw diameter after $24 \mathrm{~h}$ of CFA-induced inflammation. 


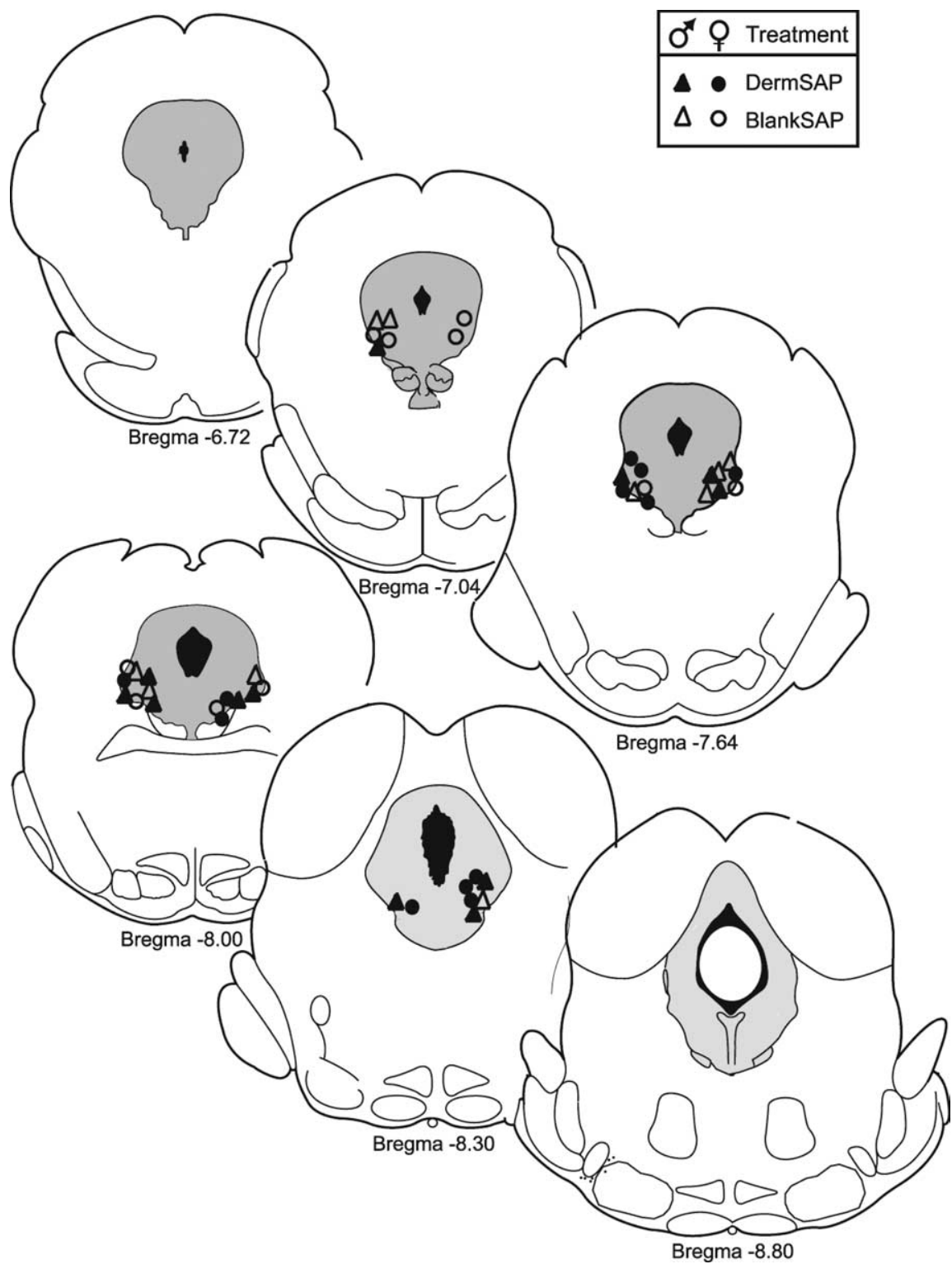

Figure 5. Illustration depicting localization of DermSAP (closed symbols) versus BlankSAP (open symbols) bilateral injection sites within the caudal ventrolateral PAG (bregma -7.04 to -8.30 ) of male (triangles) versus female (circles) rats.

scores. Unpaired $t$ tests were used to determine significant differences in baseline data. Because no significant differences in \%MPE were noted for the 30, 45, and 60 min time points, these values were averaged for derivation of $\mathrm{ED}_{50}$, defined as the dose of morphine that produced $50 \%$ of the maximum possible increase in PWL, using Prism software and analyzed for significant reductions in values using ANOVA. $p \leq$ 0.05 was considered statistically significant. Fisher's post hoc tests were used to determine specific group differences when a main effect or interaction was observed.

\section{Specific experiments}

Experiment 1. Do sex or estrous cycle influence MOR expression in the vlPAG? Male and female rats with an established $4 \mathrm{~d}$ estrous cycle were perfused transcardially with fixative on the morning of a specific stage of the estrous cycle (diestrus $1, n=12$; diestrus $2, n=12$; proestrus, $n=12$; estrus, $n=12)$. Males $(n=$ 12) and females were killed at the same time. Tissue sections were processed immunohistochemically for MOR1 immunoreactivity (Arvidsson et al., 1995; Kalyuzhny et al., 1996; Kalyuzhny and Wessendorf, 1997; 1998; Wang and Wessendorf, 1999; Kalyuzhny et al., 2000; Wang and Wessendorf, 2002) and densitometry values were recorded across vlPAG.

Experiment 2. Do sex- and estrous-cycleinduced changes in PAG MOR expression influence the analgesic effects of morphine administered into the vlPAG? Intact male and cycling female rats were implanted with cannulas directed at the ventrolateral PAG. One week later, baseline PWLs and paw diameters were determined followed by induction of CFA-induced inflammation. Twenty-four hours later, PWL and paw diameters were re-determined to ensure the presence of hyperalgesia. Saline or morphine sulfate prepared fresh on the day of experiment (obtained from the National Institute on Drug Abuse, Rockville, MD) was injected into the PAG using a syringe pump attached to a 33-gauge injector $(7 \mathrm{~mm}$; Plastics One). Separate groups of animals received morphine $(1.75,2.5,5.0,7.5,10.0,12.5,15.0,18.0$ $\mu \mathrm{g})$ or saline in a total volume of $0.5 \mu \mathrm{l}$ over

Software (BD Biosciences). The vlPAG was bilaterally sampled $\left(35 \mathrm{~mm}^{2}\right.$ at $10 \times$ magnification) between bregma -7.04 and -8.30 (Paxinos and Watson, 1997) three times per section $(6-8$ sections per brain) and the average grayscale pixel value was recorded. Measures were corrected for nonspecific immunoreactivity background by subtraction of measures taken from areas of equal size lacking specific immunoreactivity adjacent to the vlPAG in the same section. For autoradiography data, color images were captured and the brightness/contrast was adjusted using Fujifilm Multigauge software. The injection site area in the vlPAG (bregma -7.04 to -8.30 ) was sampled three times per section $(6-8$ sections per brain), averaged and the photostimulated luminescence per $\mathrm{mm}^{2}\left(\mathrm{PSL} / \mathrm{mm}^{2}\right)$ was recorded. Measures were corrected for nonspecific binding by subtraction of measures taken from a same section area adjacent to the vlPAG of equal size.

\section{Statistical analysis}

For behavioral data analysis, data are expressed as either raw PWLs or percent maximal possible effect (\%MPE), defined as [(PWL - CFA baseline) $/($ maximal PWL - CFA baseline) $] \times 100$ (Jensen and Yaksh, 1986). PWL data were analyzed for significant main effects of sex and estrous cycle using ANOVA. Percentile data were transformed into standard
$60 \mathrm{~s}$. PWLs for the inflamed paw were determined at 15,30, 45, 60, 90 and $120 \mathrm{~min}$ post injection to assess morphine analgesia. At the end of the experiment, Chicago Sky Blue dye (Sigma) was injected through the guide cannulas for injection site verification. Analysis was limited to those animals with injections into the caudal vlPAG (bregma -7.04 to -8.30 ).

Experiment 3. Do lesions of MOR-expressing neurons in the vlPAG attenuate the analgesic effects of morphine? After determination of baseline PWLs, animals were administered either DermSAP or BlankSAP bilaterally into the vlPAG. Twenty-eight days later, PWLs were determined (baseline preinflamed PWL). CFA was then injected intraplantar to induce persistent inflammatory pain. Twenty-four hours later, PWLs were determined to ensure that DermSAP had no effect on baseline hyperalgesia. Animals then received cumulative doses of morphine every $20 \mathrm{~min}$ $(1.8,3.2,5.6,8.0,10.0,18.0 \mathrm{mg} / \mathrm{kg})$, and PWLs were determined $5 \mathrm{~min}$ after administration. At the end of the experiment, animals were perfused and lesion sites verified immunohistochemically with antibodies directed against MOR1 and NeuN. An additional group of animals received either DermSAP or BlankSAP and were decapitated $28 \mathrm{~d}$ later for receptor autoradiography to examine the effectiveness of MOR lesioning. 


\section{Results}

Sex differences in $\boldsymbol{\mu}$-opioid receptor expression in the ventrolateral PAG Expression of $\mu$-opioid receptor protein in the PAG of intact male and cycling female rats was examined immunohistochemically. Within the rostral PAG, MOR immunoreactivity was localized primarily within the dorsomedial and dorsolateral subdivisions of the PAG and was comparable between the sexes. Minimal labeling was observed in the lateral PAG. Moving caudally, MOR immunoreactivity shifted and was densely localized within the lateral and vlPAG, primarily at the level of the dorsal raphe (bregma -7.04 to -8.30 ). Very little to no labeling was observed in the dorsomedial and dorsolateral PAG. Overall, females had significantly less MOR immunoreactivity in the caudal vlPAG compared with males $\left[t_{(58)}=2.18 ; p=0.0333\right.$ ] (Fig. $1 A, B)$. As shown in Figure $1 C$, MOR expression fluctuated across the estrous cycle, with reduced MOR immunoreactivity noted in proestrus females when compared with both diestrus females $(p=0.0528)$ and males $(p=0.0068)$.

\section{Intra-vlPAG morphine produces greater analgesia in males}

We have previously reported that morphine is significantly more potent in male versus female rats (Wang et al., 2006; Ji et al., 2007). Therefore, we sought to determine whether sex- and estrous cycleinduced differences in PAG MOR expression underlie behavioral differences in morphine potency. Intra-PAG cannulas were localized within the caudal vlPAG at the level of the dorsal raphe (bregma -7.04 to -8.30 ). Figure 2 shows a representative photomicrograph of the intravlPAG injection site in a male $(A)$ and female $(B)$ rat. Overall, morphine was significantly more potent in the reversal of hyperalgesia in males compared with females $\left[F_{(1,21)}=188.78 ; p<0.0001\right]$, with a significant dose by sex interaction $\left[F_{(1,21)}=21.81 ; p=0.0001\right]$. In male rats, intravlPAG morphine produced significant analgesia with administration of $10 \mu \mathrm{g}$ resulting in $100 \% \mathrm{MPE}$ at 30,45 , and $60 \mathrm{~min}$ after injection (Fig. 3A). No significant effect of morphine was observed in females at this dose. Because there were no significant differences in the \%MPE observed for the 30, 45, and 60 min time points, these data are collapsed and presented for all doses (Fig. $3 B)$. Intra-vlPAG morphine $(1.75-10 \mu \mathrm{g})$ resulted in a dosedependent analgesic response in males. The $12.5 \mu \mathrm{g}$ dose of morphine produced a $30 \% \mathrm{MPE}$ in females, and increasing the dose of morphine from 15 to $18 \mu \mathrm{g}$ did not result in a significant increase in \%MPE in females ( $~ 55 \%$ to $40 \%)$. A small group of females were administered $20 \mu \mathrm{g}$, however this dose was lethal in most animals so additional testing at this dose was terminated. Similarly, administration of the 12.5 and $15 \mu \mathrm{g}$ doses were lethal to all males so testing at this dose was terminated.
Because there was no significant difference in the \%MPE between the 12,15 , and $18 \mu \mathrm{g} / 0.5 \mu$ l doses of morphine in females, these data were collapsed and examined for a main effect of the estrous cycle on morphine analgesia. There was a significant main effect of estrous stage $\left[F_{(2,17)}=15.35 ; p=0.0002\right]$; such that proestrus $(p=0.0001)$ and estrus $(p=0.0005)$ females had significantly lower levels of morphine analgesia (20-25\%MPE), whereas diestrus females had the greatest levels of morphine analgesia (70\%MPE) (Fig. 3C). Our observed sex differences in intra-vlPAG morphine analgesia are not due to sex or estrous cycle differences in baseline thermal sensitivity $\left[F_{(3,60)}=1.027 ; p=0.3870\right]$ (Fig. $4 A$ ) or in CFA-induced hyperalgesia $\left[F_{(3,60)}=1.244 ; p=0.3017\right.$ (Fig. $4 B$ ) and there was no difference in the degree of edema produced by intraplantar CFA $\left[F_{(3,60)}=\right.$ $1.842 ; p=0.1492$ ] (Fig. 4C).

Lesions of MOR-expressing neurons in the vIPAG attenuate morphine antihyperalgesia in males only

To test the role of vlPAG MOR in driving sex differences in morphine analgesia, we injected DermSAP into the vlPAG to sitespecifically lesion MOR-expressing neurons. Lesions that were 


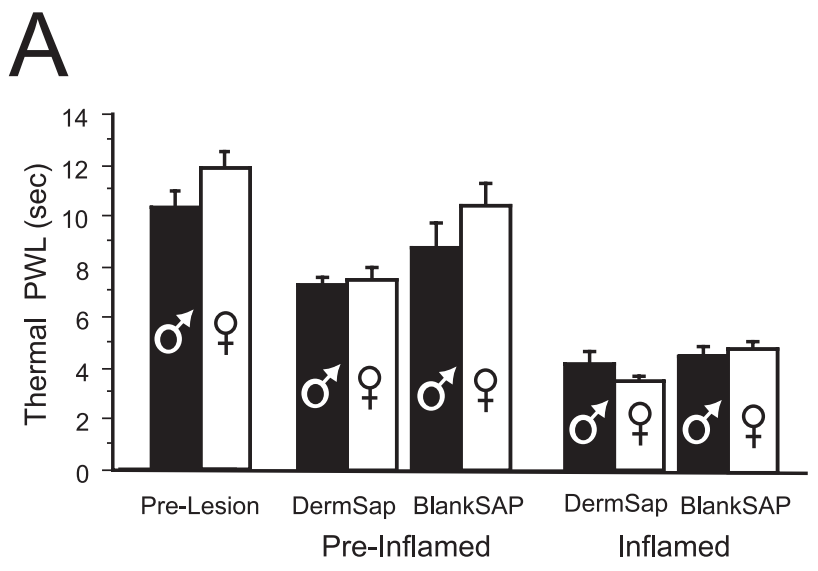

$D$

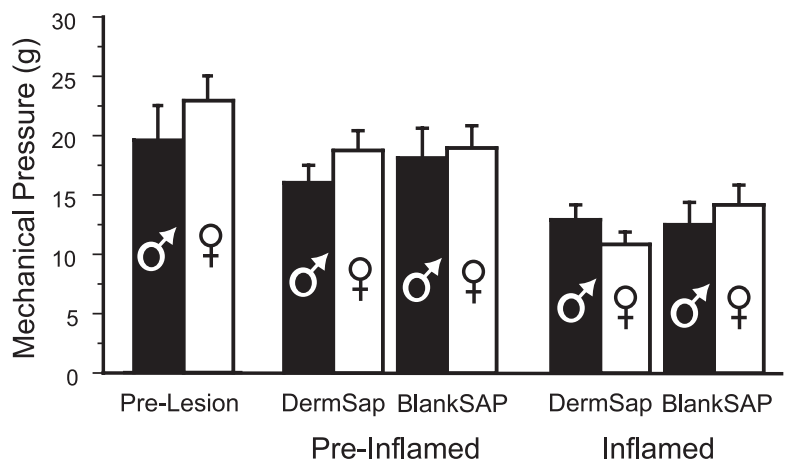

Figure 7. Paw withdrawal latencies to a thermal $(\boldsymbol{A})$ or mechanical $(\boldsymbol{B})$ painful stimulus before surgical manipulation (Pre-Lesion), after DermSAP or BlankSAP treatment (PreInflamed), and after $24 \mathrm{~h}$ of (FA-induced hyperalgesia (Inflamed) in male (closed) versus female (open) rats.

used for analysis were limited to localization within the vlPAG between bregma -7.04 and -8.30 (Fig. 5). The effectiveness of the lesions were confirmed in three ways: (1) a significant reduction in MOR immunoreactivity (Fig. 6A, $B$ ), (2) reduced neuronal nuclei immunoreactivity without complete cell loss (Fig. $6 C, D)$, and a significant reduction in tritiated DAMGO binding (Fig. 6E, F). DermSAP treatment significantly reduced MOR expression $\left[F_{(1,19)}=8.951 ; p=0.0075\right]$ and MOR agonist binding $\left[F_{(1,12)}=115.468 ; p<0.0001\right]$ in the vlPAG compared with BlankSAP controls. There was no evidence of cell necrosis due to the injection procedure in any of the animals used for analysis, similar to previous reports (Porreca et al., 2001). Lesioning MOR-expressing neurons in the vlPAG had no effect on baseline sensitivity to either a thermal $\left[F_{(1,13)}=0.193 ; p=0.6677\right]$ (Fig. $7 A$ ) or mechanical $\left[F_{(1,15)}=2.833 ; p=0.1130\right]$ (Fig. $7 B$ ) noxious stimulus in either sex. After $24 \mathrm{~h}$ of CFA-induced inflammation, there was no effect of lesions on thermal $\left[F_{(1,16)}=0.283 ; p=\right.$ $0.6018]$ (Fig. $7 A$ ) or mechanical $\left[F_{(1,16)}=0.147 ; p=0.7064\right]$ (Fig. $7 B$ ) hyperalgesia in either sex.

Twenty-four hours after the injection of CFA, the analgesic effects of morphine were assessed using a cumulative dosing paradigm. BlankSAP control male and female rats showed normal levels of morphine analgesia to cumulative doses of morphine (Fig. 8), with a mean average $\mathrm{ED}_{50}$ value of $4.07 \mathrm{mg} / \mathrm{kg}$ in males versus $10.39 \mathrm{mg} / \mathrm{kg}$ in females. There was a significant main effect of treatment $\left[F_{(3,130)}=4.750 ; p<0.0001\right]$, such that DermSAP treated males displayed a significant rightward shift in $\mathrm{ED}_{50}$ from

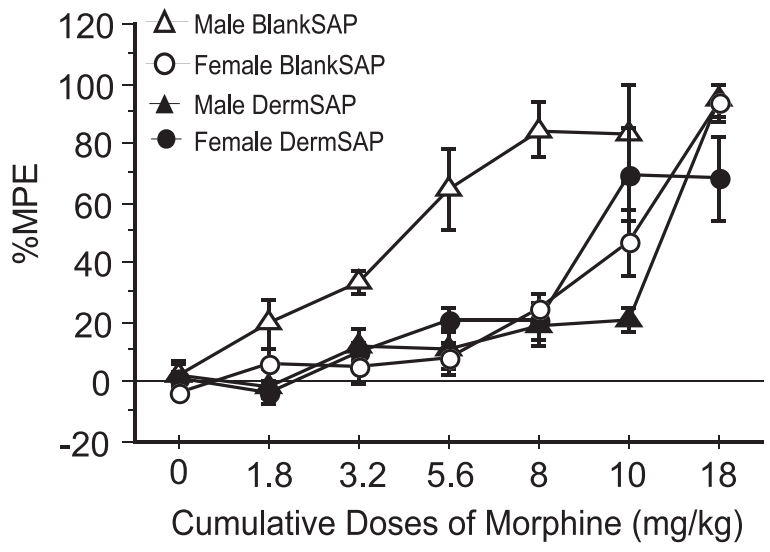

Figure 8. Percent maximal possible effect of cumulative doses of systemic morphine $(0,1.8$, $3.2,5.6,8,10,18 \mathrm{mg} / \mathrm{kg}$ ) in inflamed male (triangles) and female (circles) rats after DermSAP (closed symbols) or BlankSAP (open symbols).

$4.07 \mathrm{mg} / \mathrm{kg}$ in controls to $12.55 \mathrm{mg} / \mathrm{kg}$; no significant change in $\mathrm{ED}_{50}$ was noted in females $(10.39-9.21 \mathrm{mg} / \mathrm{kg})$.

Positive correlation between morphine analgesia and vlPAG MOR expression levels in males only

DermSAP treatment resulted in a differential loss of MOR protein across the caudal vIPAG with levels ranging from abnormally low to normal or high levels. To further examine the effect of lesioning vIPAG MOR on morphine analgesia, DermSAP and BlankSAP animals were pooled and grouped into the following three categories based on the extent of lesions: (1) abnormally low level of MOR immunoreactivity (densitometry value 49.8091.82; $n=3$ males, $n=4$ females), (2) moderate reduction of MOR immunoreactivity (93.57-121.78; $n=3$ males, $n=4$ females) and (3) normal or high levels of MOR immunoreactivity (126.48-181.33; $n=4$ males, $n=3$ females). Normal density of MOR expression was over two-fold higher than that of abnormal levels of expression (Fig. 9A). In males, there was a positive correlation between the density of vlPAG MOR-expressing neurons and the level of morphine analgesia (Fig. 9B). Reducing the expression of MOR in the vlPAG caused a significant reduction in $\mathrm{ED}_{50}$ in males: the $\mathrm{ED}_{50}$ was reduced from 3.46 in males with a high expression (group 3 ; $\mathrm{CI}=1.7-6.9)$ to 11.85 (group 1 ; $\mathrm{CI}=$ 7.04-13.9) in males with abnormally low levels of expression. There was no significant difference observed in females with a low density $\left(\mathrm{ED}_{50} 9.46\right.$; $\left.\mathrm{CI}=7.8-11.6\right)$ versus a normal 'high' density $\left(\mathrm{ED}_{50}=8.77 ; \mathrm{CI}=7.5-10.3\right)$ of MOR in the vlPAG (Fig. 9C).

\section{Discussion}

Many factors limit the potency of opiates, including tolerance (Christie et al., 1987; Morgan et al., 2003; Bagley et al., 2005; Lane et al., 2005; Loyd et al., 2008), negative side effects (Cepeda and Carr, 2003; Cepeda et al., 2003; Fillingim et al., 2005; Panchal et al., 2007) and more recently recognized, "gender" or "sex" (Wang et al., 2006). It is now well known that morphine is more potent in males compared with females; however, the mechanism(s) driving this phenomenon is unknown. The present experiments were designed to test the hypothesis that the expression of MOR in the vlPAG was sexually dimorphic and essential for eliciting sex differences in morphine potency. Here we report that (1) males have significantly higher levels of MOR protein in the vlPAG compared with females; (2) intra-vlPAG administration of morphine produces significantly greater analgesia in males; (3) lesions of 

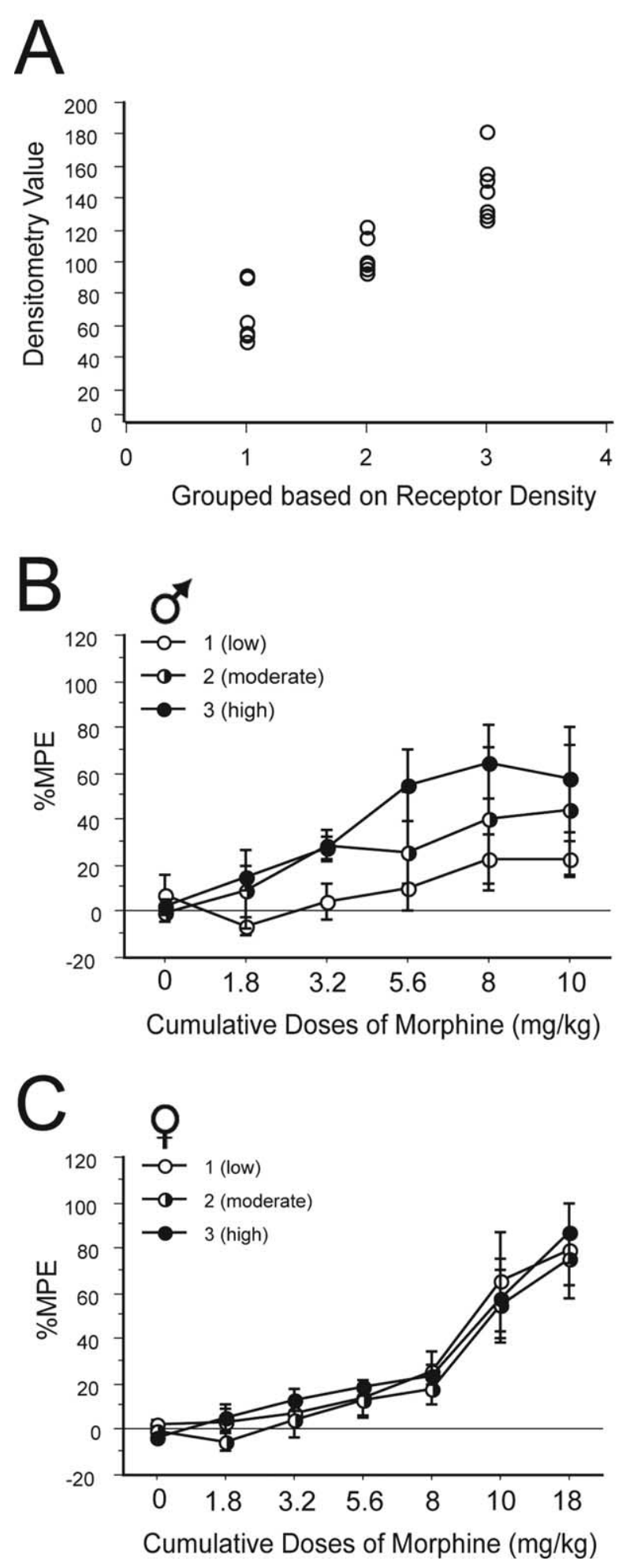

Figure 9. $A$, Densitometry value of MOR in the vIPAG of each individual male and female rat (open circle) after DermSAP or BlankSAP treatment within each group based on $\mu$-opioid receptor density. $\boldsymbol{B}, \boldsymbol{C}$, Percent maximal possible effect of cumulative doses of systemic morphine $(0,1.8,3.2,5.6,8,10,18 \mathrm{mg} / \mathrm{kg})$ in inflamed male $(\boldsymbol{B})$ and female $(\boldsymbol{C})$ rats expressing low (1), moderate (2), and high (3) $\mu$-opioid receptor density.

MOR-expressing vlPAG neurons attenuate systemic morphine analgesia in males only; and (4) the degree of morphine analgesia is positively correlated with the density of MOR immunoreactivity in the vlPAG.

\section{Sex differences in $\mu$-opioid receptor expression in the} ventrolateral PAG

In male rats, the PAG contains a high density of MOR (Mansour et al., 1986; Mansour et al., 1987; Arvidsson et al., 1995; Kalyuzhny et al., 1996; Gutstein et al., 1998; Commons et al., 1999; Commons et al., 2000; Wang and Wessendorf, 2002). Although Western blots would have provided a more quantitative approach, the present study used immunohistochemistry so that both qualitative and semiquantitative sex differences in MOR expression could be examined simultaneously within functionally distinct regions of the PAG. Here we report that the highest density of MOR immunoreactivity was observed in the caudal vlPAG, similar to previous reports (Kalyuzhny et al., 1996; Commons et al., 2000). Overall, females rats had significantly less MOR immunoreactivity in the vlPAG, with the greatest difference observed in proestrus females with approximately one-third less labeling compared with males. Interestingly, females in diestrus, the stage in which estrogen and progesterone are the lowest, had comparable levels of MOR immunoreactivity compared with males. Overall, these results are consistent with a recent Western blot study that reported twofold lower MOR protein expression in the female rat midbrain compared with males (Kren et al., 2008). These findings indicate that steroid hormones may play a role in MOR expression in the region of the PAG that is essential for analgesia and further suggests that the actions of morphine are estrous stage dependent.

\section{Intra-vlPAG morphine produces greater analgesia in males compared with estrus and proestrus females}

The antinociceptive effects of morphine are mediated primarily by the MOR, which is expressed in several supraspinal sites including the habenula, striatum, hippocampus, locus ceruleus, RVM and PAG (Arvidsson et al., 1995). Given that (1) up to 50\% of PAG-RVM projection neurons contain MOR (Commons et al., 2000; Wang and Wessendorf, 2002) and (2) female rats have reduced levels of MOR in the vlPAG, we hypothesized that differences in MOR within the PAG were sufficient to account for the sex differences in morphine analgesia. Microinjection of morphine directly into the vlPAG produced a significantly greater degree of analgesia in males compared with females at all doses tested. These results are consistent with our previous studies using systemic morphine in which $\mathrm{ED}_{50}$ values were twofold higher in female compared with male rats (Ji et al., 2006; Wang et al., 2006).

In the present study, morphine analgesia was reduced during both proestrus and estrus in comparison to diestrus and is consistent with previous studies (Kepler et al., 1989; Islam et al., 1993; Krzanowska and Bodnar, 1999; Krzanowska et al., 2002). In particular, increased levels of morphine analgesia were observed during diestrus when estrogen and progesterone are lowest. In fact, morphine analgesia during diestrus was not significantly different from males. These results parallel our findings of reduced MOR protein levels during proestrus compared with diestrus, and provide further support that the amount of available MOR is positively related to the degree of analgesia produced by morphine although other variables likely contribute. For example, while there was no significant difference in MOR expression between estrus females and males, estrus females displayed significantly less analgesia compared with males after intra-PAG morphine. This suggests that additional factors such as the activational state of the receptor also impact the ability of morphine to induce analgesia. In the present study, MOR was detected immunohistochemically, which would identify all receptors, re- 
gardless of their ability to respond to exogenous opiates. Future studies comparing the functional state of the receptor between males and females are clearly warranted.

Between 20-50\% of PAG-RVM neurons retrogradely labeled from the RVM contain receptors for the steroid hormones estrogen and androgen (Loyd and Murphy, 2008), whereas 27-50\% express MOR (Commons et al., 2000; Wang and Wessendorf, 2002); therefore it is likely that a proportion of PAG-RVM projection neurons express both receptor types. There are several mechanisms whereby changes in gonadal steroid levels could influence MOR expression and ultimately, morphine analgesia. Increased levels of estradiol result in MOR internalization (Eckersell et al., 1998; Micevych et al., 2003) and administration of estradiol results in the rapid uncoupling of MOR from G-protein-gated inwardly rectifying potassium channels (Kelly et al., 2003). Obviously, further research on the mechanism(s) whereby estradiol alters MOR expression and function is warranted.

\section{$\boldsymbol{\mu}$-Opioid-expressing neurons in the ventrolateral PAG are necessary for sex differences in morphine analgesia}

Using site-specific lesioning techniques to test the necessity of MOR-expressing neurons in eliciting sex differences in morphine analgesia, we found that reducing the density of MOR in the caudal vlPAG significantly attenuated morphine analgesia to systemic morphine in male but not female rats. The $\mathrm{ED}_{50}$ in males shifted from $4.07 \mathrm{mg} / \mathrm{kg}$ in controls to $12.55 \mathrm{mg} / \mathrm{kg}$, whereas no significant shift was noted in the $\mathrm{ED}_{50}$ in females. These data provide evidence that MOR-expressing neurons in the vlPAG are necessary for eliciting sexually dimorphic morphine potency. Removal of MOR in the vlPAG of females had no impact on morphine-induced analgesia; however, at high doses of systemic administration, morphine still produces analgesia. This suggests that in females, the PAG is not the primary anatomical substrate for the analgesic effects of morphine. Both the RVM (Porreca et al., 2001; Burgess et al., 2002) and the dorsal horn of the spinal cord (Kline and Wiley, 2008) contribute to morphine antihyperalgesia and perhaps these sites are more critical in females. In support, we have recently reported no differences in MOR expression within the lumbosacral spinal cord and similarly, no differences in $\mathrm{ED}_{50}$ values for morphine when administered intrathecally (Ji et al., 2006).

In addition, we found that the density of vlPAG MOR immunoreactivity was positively correlated with morphine analgesia in male, but not female rats. Males with normal levels of MOR immunoreactivity in the vlPAG had significantly lower $\mathrm{ED}_{50}$ values compared with males with two-fold less MOR immunoreactivity. These results further indicate that MOR-expressing neurons in the PAG are essential for morphine analgesia in male but not female rats.

Our observed sex difference in the actions of morphine is not to due sex differences in nociceptive threshold or inflammatory hyperalgesia. Interestingly, removal of vlPAG MOR with DermSAP had no effect on baseline PWL or inflammatory hyperalgesia to either a noxious thermal or mechanical stimulus. Thus, although vlPAG MOR obviously contributes to the effects of exogenous morphine, its reduction does not appear to alter endogenous pain modulation during inflammatory hyperalgesia suggesting that other pain inhibiting regions, including the RVM and spinal cord are involved. In support, previous studies have reported that DermSAP lesions of MOR-expressing neurons in the RVM (Porreca et al., 2001; Burgess et al., 2002) and dorsal horn neurons (Kline and Wiley, 2008) attenuate hyperalgesia in male rats. Together, these data indicate that the RVM and the dorsal horn of the spinal cord, but not the PAG, are essential for driving descending facilitation (Terayama et al., 2000; Ren and Dubner, 2002; Dubner and Ren, 2004; Wei et al., 2008).

Overall, our results indicate that morphine is a remarkably ineffective opiate for the alleviation of persistent pain in female rats. Sex differences in morphine potency are well known in animal research, and have also been widely reported in humans (Kest et al., 2000; Sarton et al., 2000; Zacny, 2001; Cepeda et al., 2002; Cepeda and Carr, 2003; Miller and Ernst, 2004). Interestingly, sex is not the only factor that has been shown to affect the potency of various pharmacological agents. Recent studies have reported an influence of age (Smith and Gray, 2001; Aubrun and Marmion, 2007; Gagliese et al., 2008; Hanberry and Murphy, 2008) and ethnicity (Kaiko et al., 1983), and further argue for the inclusion of a wide range of study subjects in pain management research. In addition, despite the rapidly mounting evidence of limitations of opiates in treating persistent pain in females, opioid-based drugs remain the primary pharmacological tool for pain management. Clearly additional research with the inclusion of female subjects needs to be devoted to determining a more potent treatment for persistent pain in women.

\section{References}

Abols IA, Basbaum AI (1981) Afferent connections of the rostral medulla of the cat: a neural substrate for midbrain-medullary interactions in the modulation of pain. J Comp Neurol 201:285-297.

Arvidsson U, Riedl M, Chakrabarti S, Lee JH, Nakano AH, Dado RJ, Loh HH, Law PY, Wessendorf MW, Elde R (1995) Distribution and targeting of a mu-opioid receptor (MOR1) in brain and spinal cord. J Neurosci 15:3328-3341.

Aubrun F, Marmion F (2007) The elderly patient and postoperative pain treatment. Best Pract Res Clin Anaesthesiol 21:109-127.

Bagley EE, Chieng BC, Christie MJ, Connor M (2005) Opioid tolerance in periaqueductal gray neurons isolated from mice chronically treated with morphine. Br J Pharmacol 146:68-76.

Barrett AC, Cook CD, Terner JM, Craft RM, Picker MJ (2001) Importance of sex and relative efficacy at the mu opioid receptor in the development of tolerance and cross-tolerance to the antinociceptive effects of opioids. Psychopharmacology (Berl) 158:154-164.

Bartok RE, Craft RM (1997) Sex differences in opioid antinociception. J Pharmacol Exp Ther 282:769-778.

Basbaum AI, Fields HL (1979) The origin of descending pathways in the dorsolateral funiculus of the spinal cord of the cat and rat: further studies on the anatomy of pain modulation. J Comp Neurol 187:513-531.

Basbaum AI, Clanton CH, Fields HL (1976) Opiate and stimulus-produced analgesia: functional anatomy of a medullospinal pathway. Proc Natl Acad Sci U S A 73:4685-4688.

Basbaum AI, Clanton CH, Fields HL (1978) Three bulbospinal pathways from the rostral medulla of the cat: an autoradiographic study of pain modulating systems. J Comp Neurol 178:209-224.

Behbehani MM, Fields HL (1979) Evidence that an excitatory connection between the periaqueductal gray and nucleus raphe magnus mediates stimulation produced analgesia. Brain Res 170:85-93.

Beitz AJ (1985) The midbrain periaqueductal gray in the rat. I. Nuclear volume, cell number, density, orientation, and regional subdivisions. J Comp Neurol 237:445-459.

Beitz AJ, Shepard RD (1985) The midbrain periaqueductal gray in the rat. II. A Golgi analysis. J Comp Neurol 237:460-475.

Bodnar RJ, Williams CL, Lee SJ, Pasternak GW (1988) Role of mu 1-opiate receptors in supraspinal opiate analgesia: a microinjection study. Brain Res 447:25-34.

Boyer JS, Morgan MM, Craft RM (1998) Microinjection of morphine into the rostral ventromedial medulla produces greater antinociception in male compared to female rats. Brain Res 796:315-318.

Burgess SE, Gardell LR, Ossipov MH, Malan TP Jr, Vanderah TW, Lai J, Porreca F (2002) Time-dependent descending facilitation from the rostral ventromedial medulla maintains, but does not initiate, neuropathic pain. J Neurosci 22:5129-5136. 
Cepeda MS, Carr DB (2003) Women experience more pain and require more morphine than men to achieve a similar degree of analgesia. Anesth Analg 97:1464-1468.

Cepeda MS, Africano JM, Manrique AM, Fragoso W, Carr DB (2002) The combination of low dose of naloxone and morphine in PCA does not decrease opioid requirements in the postoperative period. Pain 96:73-79.

Cepeda MS, Farrar JT, Baumgarten M, Boston R, Carr DB, Strom BL (2003) Side effects of opioids during short-term administration: effect of age, gender, and race. Clin Pharmacol Ther 74:102-112.

Christie MJ, Williams JT, North RA (1987) Cellular mechanisms of opioid tolerance: studies in single brain neurons. Mol Pharmacol 32:633-638.

Cicero TJ, Nock B, Meyer ER (1996) Gender-related differences in antinociceptive properties of morphine. J Pharmacol Exp Ther 279:767-773.

Cicero TJ, Nock B, Meyer ER (1997) Sex-related differences in morphine's antinociceptive activity: relationship to serum and brain morphine concentrations. J Pharmacol Exp Ther 282:939-944.

Commons KG, van Bockstaele EJ, Pfaff DW (1999) Frequent colocalization of mu opioid and NMDA-type glutamate receptors at postsynaptic sites in periaqueductal gray neurons. J Comp Neurol 408:549-559.

Commons KG, Aicher SA, Kow LM, Pfaff DW (2000) Presynaptic and postsynaptic relations of mu-opioid receptors to gamma-aminobutyric acid-immunoreactive and medullary-projecting periaqueductal gray neurons. J Comp Neurol 419:532-542.

Cook CD, Nickerson MD (2005) Nociceptive sensitivity and opioid antinociception and antihyperalgesia in Freund's adjuvant-induced arthritic male and female rats. J Pharmacol Exp Ther 313:449-459.

Craft RM, Kalivas PW, Stratmann JA (1996) Sex differences in discriminative stimulus effects of morphine in the rat. Behav Pharmacol 7:764-778.

Dubner R, Ren K (2004) Brainstem mechanisms of persistent pain following injury. J Orofac Pain 18:299-305.

Eckersell CB, Popper P, Micevych PE (1998) Estrogen-induced alteration of mu-opioid receptor immunoreactivity in the medial preoptic nucleus and medial amygdala. J Neurosci 18:3967-3976.

Fields HL, Basbaum AI (1978) Brainstem control of spinal paintransmission neurons. Annu Rev Physiol 40:217-248.

Fillingim RB, Ness TJ, Glover TL, Campbell CM, Hastie BA, Price DD, Staud $\mathrm{R}$ (2005) Morphine responses and experimental pain: sex differences in side effects and cardiovascular responses but not analgesia. J Pain 6:116-124.

Gagliese L, Gauthier LR, Macpherson AK, Jovellanos M, Chan VW (2008) Correlates of postoperative pain and intravenous patient-controlled analgesia use in younger and older surgical patients. Pain Med 9:299-314.

Gutstein HB, Mansour A, Watson SJ, Akil H, Fields HL (1998) Mu and kappa opioid receptors in periaqueductal gray and rostral ventromedial medulla. Neuroreport 9:1777-1781.

Hanberry R, Murphy AZ (2008) Sexually dimorphic effects of aging on morphine analgesia and $\mu$-opioid receptor binding in the periaqueductal gray of rats. Soc Neurosci Abstr 34:72.6.

Hargreaves K, Dubner R, Brown F, Flores C, Joris J (1988) A new and sensitive method for measuring thermal nociception in cutaneous hyperalgesia. Pain 32:77-88.

Islam AK, Cooper ML, Bodnar RJ (1993) Interactions among aging, gender, and gonadectomy effects upon morphine antinociception in rats. Physiol Behav 54:45-53.

Jensen TS, Yaksh TL (1986) III. Comparison of the antinociceptive action of $\mathrm{mu}$ and delta opioid receptor ligands in the periaqueductal gray matter, medial and paramedial ventral medulla in the rat as studied by microinjection technique. Brain Res 372:301-312.

Ji Y, Murphy AZ, Traub RJ (2006) Sex differences in morphine-induced analgesia of visceral pain are supraspinally and peripherally mediated. Am J Physiol Regul Integr Comp Physiol 291:R307-R314.

Ji Y, Murphy AZ, Traub RJ (2007) Estrogen modulation of morphine analgesia of visceral pain in female rats is supraspinally and peripherally mediated. J Pain 8:494-502.

Kaiko RF, Wallenstein SL, Rogers AG, Houde RW (1983) Sources of variation in analgesic responses in cancer patients with chronic pain receiving morphine. Pain 15:191-200.

Kalyuzhny AE, Wessendorf MW (1997) CNS GABA neurons express the mu-opioid receptor: immunocytochemical studies. Neuroreport 8:3367-3372.

Kalyuzhny AE, Wessendorf MW (1998) Relationship of mu- and deltaopioid receptors to GABAergic neurons in the central nervous system, including antinociceptive brainstem circuits. J Comp Neurol 392:528-547.

Kalyuzhny AE, Arvidsson U, Wu W, Wessendorf MW (1996) $\mu$-Opioid and $\delta$-opioid receptors are expressed in brainstem antinociceptive circuits: studies using immunocytochemistry and retrograde tract-tracing. J Neurosci 16:6490-6503.

Kalyuzhny AE, Dooyema J, Wessendorf MW (2000) Opioid- and GABA(A)-receptors are co-expressed by neurons in rat brain. Neuroreport 11:2625-2628.

Kelly MJ, Qiu J, Ronnekleiv OK (2003) Estrogen modulation of G-protein coupled receptor activation of potassium channels in the central nervous system. Ann N Y Acad Sci 1007:6-16.

Kepler KL, Kest B, Kiefel JM, Cooper ML, Bodnar RJ (1989) Roles of gender, gonadectomy and estrous phase in the analgesic effects of intracerebroventricular morphine in rats. Pharmacol Biochem Behav 34:119-127.

Kest B, Wilson SG, Mogil JS (1999) Sex differences in supraspinal morphine analgesia are dependent on genotype. J Pharmacol Exp Ther 289:1370-1375.

Kest B, Sarton E, Dahan A (2000) Gender differences in opioid-mediated analgesia: animal and human studies. Anesthesiology 93:539-547.

Kline RH 4th, Wiley RG (2008) Spinal $\mu$-opioid receptor-expressing dorsal horn neurons: role in nociception and morphine antinociception. J Neurosci 28:904-913.

Kren MC, Haller VL, Welch SP (2008) The role of gonadal hormones on opioid receptor protein density in arthritic rats. Eur J Pharmacol 578:177-184.

Krzanowska EK, Bodnar RJ (1999) Morphine antinociception elicted from the ventrolateral periaqueductal gray is sensitive to sex and gonadectomy differences in rats. Brain Res 821:224-230.

Krzanowska EK, Ogawa S, Pfaff DW, Bodnar RJ (2002) Reversal of sex differences in morphine analgesia elicited from the ventrolateral periaqueductal gray in rats by neonatal hormone manipulations. Brain Res 929:1-9.

Lane DA, Patel PA, Morgan MM (2005) Evidence for an intrinsic mechanism of antinociceptive tolerance within the ventrolateral periaqueductal gray of rats. Neuroscience 135:227-234.

Loyd DR, Murphy AZ (2006) Sex differences in the anatomical and functional organization of the periaqueductal gray-rostral ventromedial medullary pathway in the rat: a potential circuit mediating the sexually dimorphic actions of morphine. J Comp Neurol 496:723-738.

Loyd DR, Murphy AZ (2008) Androgen and estrogen receptor localization on periaqueductal gray-rostral ventromedial medullary neurons in the male and female rat. J Chem Neuroanat 36:216-226.

Loyd DR, Morgan MM, Murphy AZ (2007) Morphine preferentially activates the periaqueductal gray-rostral ventromedial medullary pathway in the male rat: a potential mechanism for sex differences in antinociception. Neuroscience 147:456-468.

Loyd DR, Morgan MM, Murphy AZ (2008) Sexually dimorphic activation of the periaqueductal gray-rostral ventromedial medullary circuit during the development of tolerance to morphine in the rat. Eur J Neurosci 27:1517-1524.

Ma QP, Han JS (1991) Naloxone blocks the release of opioid peptides in periaqueductal gray and N. accumbens induced by intra-amygdaloid injection of morphine. Peptides 12:1235-1238.

Mansour A, Lewis ME, Khachaturian H, Akil H, Watson SJ (1986) Pharmacological and anatomical evidence of selective mu, delta, and kappa opioid receptor binding in rat brain. Brain Res 399:69-79.

Mansour A, Khachaturian H, Lewis ME, Akil H, Watson SJ (1987) Autoradiographic differentiation of $\mathrm{mu}$, delta, and kappa opioid receptors in the rat forebrain and midbrain. J Neurosci 7:2445-2464.

Micevych PE, Rissman EF, Gustafsson JA, Sinchak K (2003) Estrogen receptor-alpha is required for estrogen-induced mu-opioid receptor internalization. J Neurosci Res 71:802-810.

Miller PL, Ernst AA (2004) Sex differences in analgesia: a randomized trial of mu versus kappa opioid agonists. South Med J 97:35-41.

Morgan MM, Clayton CC, Lane DA (2003) Behavioral evidence linking opioid-sensitive GABAergic neurons in the ventrolateral periaqueductal gray to morphine tolerance. Neuroscience 118:227-232.

Murphy AZ, Hoffman GE (2001) Distribution of gonadal steroid receptorcontaining neurons in the preoptic-periaqueductal gray-brainstem pathway: a potential circuit for the initiation of male sexual behavior. J Comp Neurol 438:191-212. 
Okamoto K, Tashiro A, Hirata H, Bereiter DA (2005) Differential modulation of TMJ neurons in superficial laminae of trigeminal subnucleus caudalis/upper cervical cord junction region of male and cycling female rats by morphine. Pain 114:203-211.

Panchal SJ, Müller-Schwefe P, Wurzelmann JI (2007) Opioid-induced bowel dysfunction: prevalence, pathophysiology and burden. Int J Clin Pract 61:1181-1187.

Paxinos G, Watson C (1997) The rat brain in stereotaxic coordinates. New York: Academic.

Porreca F, Burgess SE, Gardell LR, Vanderah TW, Malan TP Jr, Ossipov MH, Lappi DA, Lai J (2001) Inhibition of neuropathic pain by selective ablation of brainstem medullary cells expressing the $\mu$-opioid receptor. J Neurosci 21:5281-5288.

Ren K, Dubner R (2002) Descending modulation in persistent pain: an update. Pain 100:1-6.

Sarton E, Olofsen E, Romberg R, den Hartigh J, Kest B, Nieuwenhuijs D, Burm A, Teppema L, Dahan A (2000) Sex differences in morphine analgesia: an experimental study in healthy volunteers. Anesthesiology 93:1245-1254.

Satoh M, Kubota A, Iwama T, Wada T, Yasui M, Fujibayashi K, Takagi H (1983) Comparison of analgesic potencies of mu, delta and kappa agonists locally applied to various CNS regions relevant to analgesia in rats. Life Sci 33:689-692.

Shah Y, Dostrovsky JO (1980) Electrophysiological evidence for a projection of the periaqueductal gray matter to nucleus raphe magnus in cat and rat. Brain Res 193:534-538.

Smith MA, Gray JD (2001) Age-related differences in sensitivity to the antinociceptive effects of opioids in male rats. Influence of nociceptive intensity and intrinsic efficacy at the mu receptor. Psychopharmacology (Berl) 156:445-453.

Starowicz K, Maione S, Cristino L, Palazzo E, Marabese I, Rossi F, de Novellis V, Di Marzo V (2007) Tonic endovanilloid facilitation of glutamate re- lease in brainstem descending antinociceptive pathways. J Neurosci 27:13739-13749.

Terayama R, Guan Y, Dubner R, Ren K (2000) Activity-induced plasticity in brain stem pain modulatory circuitry after inflammation. Neuroreport 11:1915-1919.

Vera-Portocarrero LP, Zhang ET, Ossipov MH, Xie JY, King T, Lai J, Porreca F (2006) Descending facilitation from the rostral ventromedial medulla maintains nerve injury-induced central sensitization. Neuroscience 140:1311-1320.

Wang H, Wessendorf MW (1999) Mu- and delta-opioid receptor mRNAs are expressed in spinally projecting serotonergic and nonserotonergic neurons of the rostral ventromedial medulla. J Comp Neurol 404:183-196.

Wang H, Wessendorf MW (2002) Mu- and delta-opioid receptor mRNAs are expressed in periaqueductal gray neurons projecting to the rostral ventromedial medulla. Neuroscience 109:619-634.

Wang X, Traub RJ, Murphy AZ (2006) Persistent pain model reveals sex difference in morphine potency. Am J Physiol Regul Integr Comp Physiol 291:R300-R306.

Watson RE, Wiegand SJ, Clough RW, Hoffman GE (1986) Use of cryoprotectant to maintain longterm peptide immunoreactivity and tissue morphology. Peptides 7:155-159.

Wei F, Guo W, Zou S, Ren K, Dubner R (2008) Supraspinal glial-neuronal interactions contribute to descending pain facilitation. J Neurosci 28: 10482-10495.

Wilcox RE, Mikula JA, Levitt RA (1979) Periaqueductal gray naloxone microinjections in morphine-dependent rats: hyperalgesia without "classical" withdrawal. Neuropharmacology 18:639-641.

Zacny JP (2001) Morphine responses in humans: a retrospective analysis of sex differences. Drug Alcohol Depend 63:23-28.

Zhang Y, Du LN, Wu GC, Cao XD (1998) Modulation of intrathecal morphine-induced immunosuppression by microinjection of naloxone into periaqueductal gray. Zhongguo Yao Li Xue Bao 19:519-522. 